\title{
Article
}

\section{Training Service Staff to Enhance Non-Verbal Behavioral Skills to Increase Customer Profitability in Tourism}

\author{
Claudia C. Tusell-Rey ${ }^{1}$, Carmen F. Rey-Benguría ${ }^{2}$, Ricardo Tejeida-Padilla ${ }^{1}\left[\right.$ and Yenny Villuendas-Rey ${ }^{3, *(D)}$ \\ 1 Escuela Superior de Turismo del Instituto Politécnico Nacional, Miguel Bernard 39, La Purísima Ticoman, \\ GAM, Mexico City 07630, Mexico; ctusellr2100tmp@alumnoguinda.mx (C.C.T.-R.); rtejeidap@ipn.mx (R.T.-P.) \\ 2 Center for Educational Studies "José Martí", University of Ciego de Ávila, km 91/2, \\ 65100 Ciego de Ávila, Cuba; carmenrb2008@gmail.com \\ 3 Centro de Innovación y Desarrollo Tecnológico en Cómputo del Instituto Politécnico Nacional, Juan de Dios \\ Bátiz s/n, GAM, Mexico City 07700, Mexico \\ * Correspondence: yvilluendasr@ipn.mx; Tel.: +52-5729600 (ext. 56584)
}

Citation: Tusell-Rey, C.C.;

Rey-Benguría, C.F.; Tejeida-Padilla, R.; Villuendas-Rey, Y. Training Service Staff to Enhance Non-Verbal Behavioral Skills to Increase Customer Profitability in Tourism. Tour. Hosp. 2021, 2, 233-247. https:// doi.org/10.3390/tourhosp2020014

Academic Editor: Brian Garrod

Received: 14 April 2021

Accepted: 19 May 2021

Published: 21 May 2021

Publisher's Note: MDPI stays neutral with regard to jurisdictional claims in published maps and institutional affiliations.

Copyright: (c) 2021 by the authors. Licensee MDPI, Basel, Switzerland. This article is an open access article distributed under the terms and conditions of the Creative Commons Attribution (CC BY) license (https:/ / creativecommons.org/licenses/by/ $4.0 /)$.

\begin{abstract}
To address the personalization of customer service in four-star hotels in Cuba, this research takes up the precepts of non-verbal communication and Customer Relationship Management. The Systemic Method and its treatment through the Soft Systems Methodology are applied. With information obtained from the Sol Cayo Guillermo hotel, belonging to the Jardines del Rey tourist center, in Cuba, a grouping of the essential elements in customer satisfaction generated with the use of Computational Intelligence algorithms was used. In the end, we introduce a training program for the personalization of customer service based on the non-verbal communication system to enhance service in four-star hotels in Cuba. As a main result, the experts agree that the proposed training program will have a positive impact on the worker-client communication relationship to increase customer profitability in four-star hotels in Cuba.
\end{abstract}

Keywords: staff training; non-verbal skills; computational intelligence; customer relationship management

\section{Introduction}

The purpose of tourism organizations is to guarantee customer satisfaction, which, as a dynamic factor in the functional structure of the tourism sector, has evolved in correspondence with new paradigms and trends, which are characterized by a growing individualization of the trip, greater participation in the conformation of the tourist experience, and higher quality standards.

Currently, tourists are more demanding, are better informed, and require greater attention [1]. That is why in tourism organizations, the customer relationship management paradigm (Customer Relationship Management, CRM) is fundamental [2,3]. With the emergence of the new technologies of information and communication, CRM has evolved in the digital age, giving way to electronic CRM (eCRM), where marketing activities have at least one virtual component.

Dubihlea and Molise-Khosa proposed a model [4] of the influence of eCRM implementation on customer profitability. Several dimensions or attributes of eCRM have been identified $[1,5,6]$, such as customer service quality, information quality, personalization level, perceived trust, and others. In customer service, the analysis of information and adequate communication are fundamental tools to achieve their entire satisfaction. Modern technologies provide new business opportunities in the establishment, improvement, and commercialization of relationships with customers, to fully understand and satisfy their needs [7-11].

Recent studies show a close relation between loyalty programs and information and communication, to increase the effectiveness of such programs, thus increasing customer 
profitability [12]; in addition, it was shown that information communication and CRM can positively influence the purchase behavior of customers [13], as well as having positive and significant impact in the relations with the clients [14].

The impact to staff training in the productivity and profitability of organizations has been addressed in the literature [15], showing that training programs devoted to the improvement of skills, attitudes, knowledge, and competencies of the employees, lead to advances in productivity, effectiveness, and efficiency of organizations.

In this research, we start from the theoretical thesis that addresses communication as a process that, within the framework of the tourist institution, characterizes the expression that gives stability to the subject in their interpersonal relationships depending on the social significance they have for the subject and the circumstances in which that communication takes place. Therefore, according to the communication system that is built, this is the meaning it has for the subject and does or does not act as an element of development for it. As a process, new needs and perceptions are fostered in the relationships with the clients who participate in it, so that the professionals who attend to them in the institutions, support a process of open communication, of mutual empowerment, in favor of the quality of the process.

Non-verbal communication influences the perception of the subjects when communicating with each other. This perception includes the messages that are transmitted through personal appearance, clothing, posture, gestures, eyes, and everything that can disqualify or affirm what is said with words [16-20]. In this way, in the action of the staff which relates to customers, it is as important to know how to structure the discourse as well as to combine non-verbal elements in order to emphasize the issues on which it needs to draw attention. Thus, the need to efficiently handle both the verbal and the non-verbal is manifested. This professional must be aware that everything in the body "speaks" [21].

All researchers on this subject agree on the need to make the communication process with the client more effective, in order to facilitate communication success and conflict resolution, thus speaking of the need to train certain skills in professionals. Despite the importance of non-verbal communication in social interaction processes in general and in customer service, research on this topic has not had frequent addresses in tourism.

An interesting study in the topic is the one by Koc and Boz [22], who explore the influence of training tourism employees abilities in the recognition of emotions. Their research shows that their program "improved the emotion/facial expression recognition abilities of tourism and hospitality employees significantly both in terms of accuracy and speed" [22], leading to an improvement in the employees' interactions with customers and with other employees. In addition, the study of Sharma also addresses some non-verbal aspects of communication (related with self-presentation) in a training program for tourism guides in Nepal [23].

In the context of the study interest that is Cuba, the country maintains, according to official data from the National Statistics Office, its trajectory as a recipient of tourism. During 2019, it received more than three million tourists. Therefore, the position is assumed that despite the fact that the tourism system in Cuba has dealt with the problem of customer satisfaction, as the main function of the tourism institution, in practice the challenge of customizing the process is not fully evidenced, attending to those aspects of preference that are usually related to elements of the non-verbal component of communication.

To address the personalization of customer service in four-star hotels in Cuba, this research takes up the precepts of non-verbal communication and Customer Relationship Management (CRM), which is a management approach that focuses on the customer and satisfaction of their needs. This fully justifies our proposal due to the need for the inclusion of elements of non-verbal communication and its consensual use as a support tool for the customer service staff in Cuba.

The goal of the paper is to introduce a training program to increase the preparation of the hotel staff, for personalized attention to the client, taking into account their non-verbal preferences. 
To achieve the purpose, the Systemic Method and its treatment through the Soft Systems Methodology are applied. With information obtained from the Sol Cayo Guillermo hotel, belonging to the Jardines del Rey tourist center, in Cuba, a grouping of the essential elements in customer satisfaction generated with the use of Computational Intelligence algorithms was used. In the end, we introduce a training program for the personalization of customer service based on the non-verbal communication system to enhance service in four-star hotels in Cuba.

\section{Materials and Methods}

The information obtained from customers can be varied, dispersed, and with high volumes of data. In this research, reference is made to the analysis of information in two aspects within the CRM: customer satisfaction and the study of customer behavior. We used the Soft Systems Methodology (SSM) [24] in our research, and a brief overview of our approach is given in Figure 1. We start with the data regarding the non-verbal preferences of the customers, and we analyze the characteristics of the non-verbal preferences of each of the six clusters of clients. Then, we outline actions to give the staff the theoretical knowledge and the practical skills needed to adequately communicate with each type of client, according to their non-verbal preferences. We design a training program, to improve the staff skills and then improve their communication abilities.

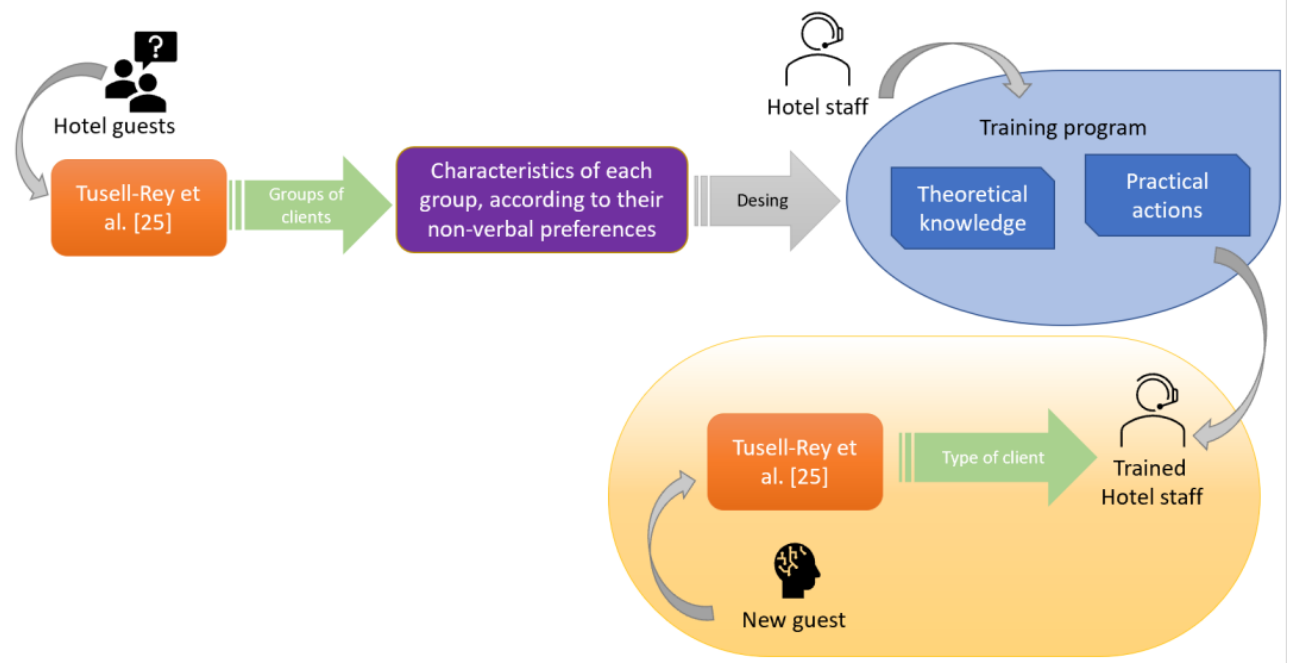

Figure 1. Overview of the research methodology followed.

We use the dataset obtained by Tusell-Rey et al. regarding the non-verbal preferences of the Sol Cayo Guillermo hotel [25], in order to determine the non-verbal preferences of the clients and then to propose a personalized attention program according to such preferences.

The dataset includes the responses of 73 customers, between 24 and 81 years of age, regarding their non-verbal preferences measures by means of 22 variables, including their perceptions about images, videos, and audios. All of the individuals in the dataset answered a questionnaire [25], and their non-verbal preferences were assessed accordingly.

The use of clustering techniques allows Tusell-Rey et al. to find six types (clusters) of clients, according to their preferences. The corresponding cluster identification of each client is also included in the dataset. The distribution of clients in the clusters (Figure 2) is imbalanced, which is shown by the corresponding percentages in Figure 2. 


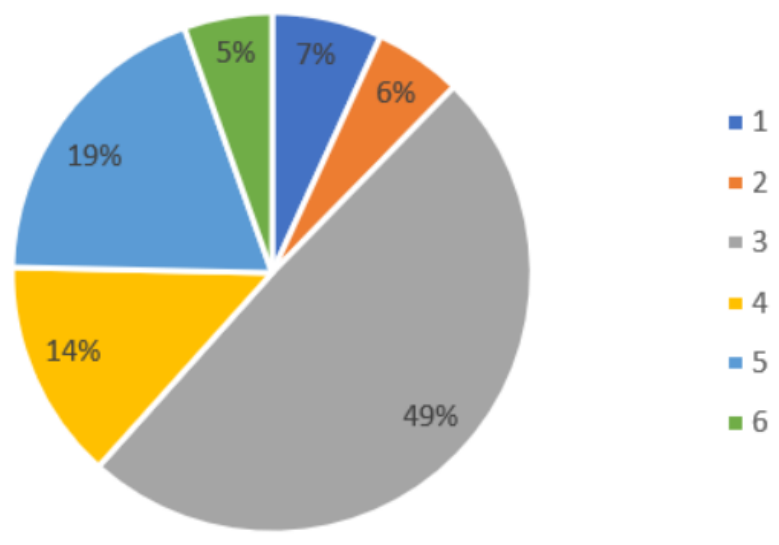

Figure 2. Percent of hotel guests in the clusters found by Tusell-Rey et al. [25].

As stated before, the research of [25] identified six types of clients, according to their non-verbal preferences. In the following, we offer a brief description of such clusters of clients.

Cluster 1: The clients in this cluster prefer a formal and distant treatment, as well as a friendly voice tone.

Cluster 2: These clients like social or personal distances and like the staff's gestures.

Cluster 3: Mostly formed by returning clients, who prefer intimate distance, as well as interactions with the staff.

Cluster 4: Also formed by returning clients, who prefer a personal distance in their interactions and dislike the quasi-lexical elements of the staff.

Cluster 5: Formed by clients who prefer a social or public distance in their interactions and who dislike any expression of sympathy and interest from the staff.

Cluster 6: Clients who require non-verbal behavior of the staff to be servile, any other behavior is perceived as conflictive.

To design a training program to increase the preparation of the hotel staff for personalized attention to the client, taking into account their non-verbal preferences, we used the Soft Systems Methodology (SSM) [24], which is a flexible methodology that seeks the phenomenological interpretation of the activities of the actors and their interrelationships and was proposed by Peter Checkland in 1972 and later refined [26]. This methodology encompasses key elements in the study of systems and has been addressed in numerous scientific articles [27-30]. The SSM is particularly useful for capturing the systemic complexities within an organization [31,32]. The SSM has two phases, which group seven elements.

By using a phenomenological-hermeneutical method, a representation is generated within the research of a new perspective of concepts related to and associated with tourism, which are supported by hermeneutical theories and systems theories. First-hand, feasible information is sought, and favorable solutions are proposed to help or improve the theoretical aspects studied. These elements allow the organization of epistemological concepts and criteria, for the proper understanding of the relationships of the context of tourist attractions and of communicative action with a systemic approach.

This research is supported by systemic-hermeneutical precepts such as the conception of the search for a research approach that helps to understand efficient communicative actions and seeks a systemic structure for the personalization system.

\section{Results}

By following the results of the clustering obtained by Tusell-Rey et al. [25], we were able to design a training program including both theoretical knowledge and practical actions to give the personnel of the system under study (the Sol Cayo Guillermo hotel at Jardines del Rey, Cuba) the necessary qualifications about the clients' non-verbal prefer- 
ences, according to the six clusters of clients. This training program is explained in this section.

Training programs are considered to be a contribution of the research [33] and are classified as a result of practical significance. This is due to the fact that the training programs are aimed at planning the transformation process of a certain object or study group, from a current state to an ambitious state. To do this, a planned process is conducted that includes actions, goals, and a period to develop them.

That is why training programs are conscious, intentional, planned, and aimed at solving problems in practice, which must be executed within a predetermined period of time and which allow the evaluation of the results obtained [34].

This research proposes the development of a training program. Training is defined as a permanent, systematic, and planned process, which is based on real or prospective deficiencies of the company, social group, or others. This process is focused on a change either in the knowledge, behaviors, skills, qualities, or behaviors of the individuals who are trained, enabling their development. Finally, the workers increased their professional skills and the effectiveness of their labor [35-37].

\subsection{Structure and Characterization of the Training Program}

For the development of the proposal, the potentialities and limitations of the system under study were decided. The potentialities found were:

- The system under study is in a recognized tourist destination with excellent natural conditions.

- There is a high sense of relevance of the hotel community toward the tourist destination.

- Workers have a great commitment to the work they do.

- The hotel staff has a positive disposition toward self-improvement.

- There is the possibility of improving customer profitability.

The limitations found are expressed in the lack of training for hotel workers and in the deficient worker-client communication strategies.

The training program developed is based on the principles of strategic direction, which were analyzed by the author based on the results of the first diagnosis and the goal of the training program. The characteristics of the proposal are:

- Contextualized: The training program in its conception proposes the actions in the specific contents that the personnel who work in the hotel need, based on the potentialities and needs derived from the diagnosis conducted.

- Personalized: Responds to the particularities of the clients' personalities and their non-verbal communication preferences.

- Objective: The training program is planned so that its realization and assessment are based on the real possibilities of its execution, considering contextual, personalized, and dynamic elements.

- $\quad$ Systemic: It allows the orderly, coherent, and linked mix of all the actors and components in the worker-client interaction process.

Using the Soft Systems Methodology, two relevant systems were considered, and these were operationalized in the proposed training program (Figure 3). 


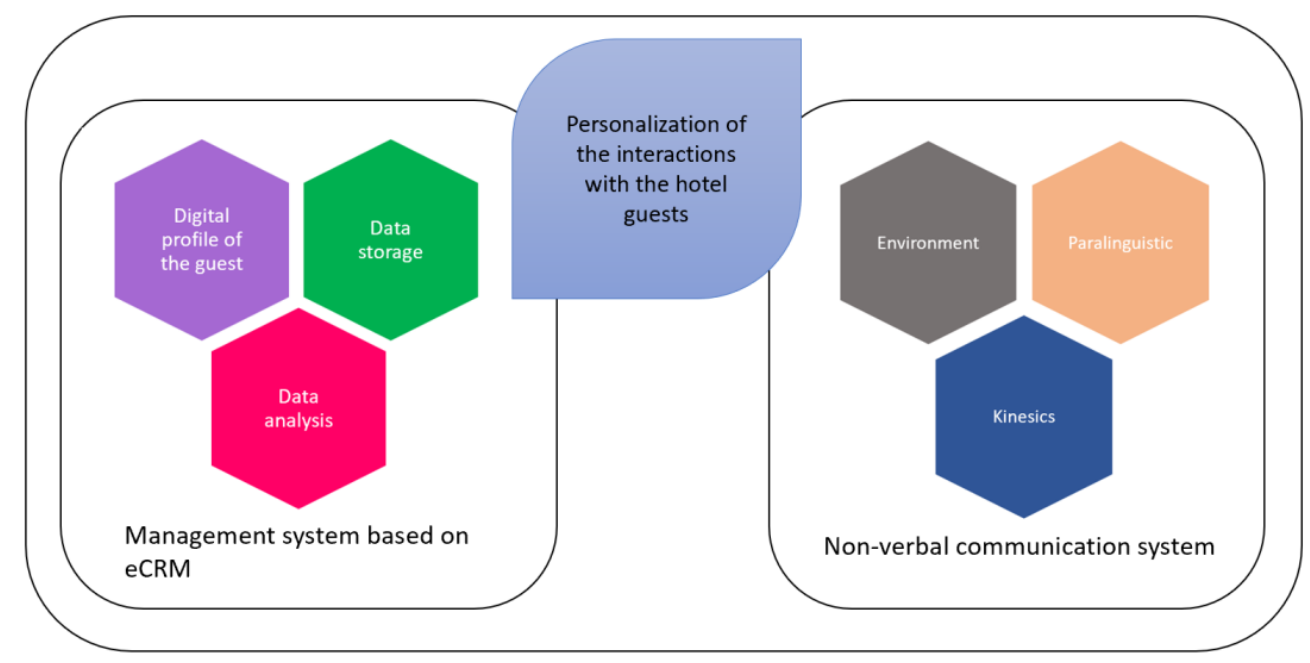

Figure 3. Integration of relevant systems in the proposed training program.

\subsection{Stages of the Training Program}

The training program requires a general goal: to increase the preparation of the staff of the Sol Cayo Guillermo hotel, for personalized attention to the client, taking into account their non-verbal preferences. It is structured in three stages related through the actions that are proposed and can be adapted to other contexts where the shortcomings for which it has been made are manifested, meaning it has a referential character. The first stage focuses on the creation of the conditions prior to the development of the training program, the second on its execution, and the third on its evaluation. These stages are described in this section.

FIRST STAGE: Creation of the preconditions for the implementation of the training program.

OBJECTIVE OF THE STAGE: To ensure the preconditions for the implementation of the training program based on the preparation of the personnel.

In this stage, the different actions are planned, the material preconditions are ensured, in terms of human potential, resource planning is coordinated with the actors, and the instrument is applied and tabulated, among other actions. This period is essential to sensitize all participating agents with the need of applying the training program, taking into account social demand to increase customer profitability. The proposed actions (1-3) are offered in Table 1.

SECOND STAGE: Realization of the training program.

OBJECTIVE OF THE STAGE: To develop training actions for personnel.

At this stage, it is proposed to deploy a space for exchange and deliberation, through a general meeting, in which the selected workers take part. It specifically explains what the preparation for personalized customer service consists of, what aspects are assumed in the training program, how long it lasts, what actions and stages are included, and the theoretical and practical elements that are addressed. The opinions of the participants will be analyzed, considering their preparation needs about the subject under investigation. The actions of this stage (4-6) are shown in Table 1.

From Action 4 the following characteristics of the groups of guests can be determined:

Group 1 . They are characterized by being distant people; they prefer a formal treatment; and they dislike expressions of affection (kisses and hugs). This group prefers the interested and consenting positions, and they are uncomfortable with the negative position. They consider the emotional atmosphere to be relaxed; interaction is considered hostile. They reject the authoritarian and sarcastic tone. They are uncomfortable with quasi-lexical elements. 
Table 1. Actions of the proposed training program.

\begin{tabular}{|c|c|c|c|}
\hline Action & Title & Objectives & Participants/Time \\
\hline 1 & $\begin{array}{l}\text { Design and application of the } \\
\text { questionnaire }\end{array}$ & $\begin{array}{l}\text { Find the attributes to measure and the } \\
\text { non-verbal preferences of hotel guests. }\end{array}$ & Researchers/Two months \\
\hline 2 & $\begin{array}{l}\text { Clustering of the non-verbal } \\
\text { preferences }\end{array}$ & Find the clusters of clients. & Researchers/One week \\
\hline 3 & Meeting with the hotel's staff & $\begin{array}{l}\text { Sensitize staff with the need to apply } \\
\text { the training program. }\end{array}$ & Researchers and staff/One day \\
\hline 4 & $\begin{array}{c}\text { Characterization of the non-verbal } \\
\text { preferences of the clusters }\end{array}$ & $\begin{array}{l}\text { Describe the non-verbal preferences of } \\
\text { each cluster of guests }\end{array}$ & $\begin{array}{l}\text { Researchers and experts of the } \\
\text { Customer Service } \\
\text { Department/One month }\end{array}$ \\
\hline 5 & $\begin{array}{l}\text { Design of the personalized } \\
\text { non-verbal behavior }\end{array}$ & $\begin{array}{l}\text { Project personalized attention to } \\
\text { customer groups }\end{array}$ & $\begin{array}{l}\text { Researchers, experts of the } \\
\text { Customer Service Department } \\
\text { and expert in non-verbal } \\
\text { behavior/One month }\end{array}$ \\
\hline 6 & Training workshops & $\begin{array}{c}\text { Enhance the theoretical preparation of } \\
\text { hotel workers }\end{array}$ & $\begin{array}{l}\text { Researchers, expert in non-verbal } \\
\text { behavior and staff/One month }\end{array}$ \\
\hline 7 & Feedback & $\begin{array}{l}\text { Corroborate the preparation of hotel } \\
\text { workers, through customer satisfaction }\end{array}$ & Researcher/One month \\
\hline 8 & Self-transformation record & $\begin{array}{l}\text { Assess the level of metacognition } \\
\text { reached by the workers, as well as the } \\
\text { efficacy of the preparations received }\end{array}$ & Researcher and staff/One day \\
\hline
\end{tabular}

Group 2. They prefer personal distance. They like expressions of affection the staff toward them. They like positions of consent and interest; they are indifferent to neutral positions; and they are uncomfortable with negative ones. This group perceives the emotional atmosphere as very relaxed and the interaction friendly. This group is indifferent to the authoritarian tone. They are uncomfortable with quasi-lexical elements uhm and ay, and they are indifferent to oil-spitting. Group 3. They are characterized by being repeaters. They are clients adapted to Cuban cultural dynamics, including linguistics. This makes them receptive to staff interactions. They prefer an intimate relationship, given in the preference for a proxemics of this type. They like the expressions of affection of kisses and hugs. The preferred positions are those of consent, neutral, reflective, and of interest. They are uncomfortable with the negative posture. They perceive the emotional environment as relaxed. They are uncomfortable with the authoritarian tone and are indifferent to the sarcastic one. They are not bothered by the quasi-lexical elements heard.

Group 4. They are also repeat customers but prefer a more personal rather than intimate distance. They are indifferent to gestures of affection such as kisses and hugs, but they like the handshake. They like consenting, caring, and neutral positions. The reflective ones are indifferent to him. They perceive the emotional atmosphere relaxed (between 1 and 3 on the presented scale) and friendly (between 1 and 3 on the presented scale). They are uncomfortable with the authoritarian tone; they are indifferent to the sarcastic, and they like the friendly. They are bothered by using the quasi-lexical items evaluated.

Group 5. They are people who prefer a social or even public proximity. They are uncomfortable with expressions of affection (kisses, hugs) and are indifferent even to the handshake. They reject neutral, reflective, and negative positions on the part of the staff. They describe the emotional atmosphere of the hotel as neutral, that is, neither tense nor relaxed, and they consider the situation presented as hostile. They reject the authoritarian tone, and they like the friendly one. They are uncomfortable with all the quasi-lexical items shown.

Group 6. They are uncomfortable with all expressions of affection They like positions of consent and are uncomfortable with others. They value the emotional environment tending toward tense (between 6 and 7 on the presented scale). They perceive the interaction 
as hostile (between 7 and 8 on the presented scale). They prefer distance to be intimate. They are uncomfortable with the authoritarian tone; and they are indifferent to the tone of the friendly and sarcastic tone. They are uncomfortable with the quasi-lexical elements heard. Unlike the earlier ones, these individuals usually consider any other type of nonverbal gestures such as illustrators, used by the staff as aggressive and conflict-generating language.

From Action 5, a set of custom actions were figured out for each customer group, which are described below.

Group 1. The treatment of this group must be very formal, without excessive expressions that denote annoyance or sarcasm, not a very friendly treatment either.

Group 2. They must show an affable treatment, avoid sudden movements, keep personal distance, and take care that the tone is not imperative or ironic. They should refrain from speaking to other workers in an authoritative tone in the presence of clients.

Group 3. The staff can, with this group, have an intimate and friendly treatment, and they are also very pleased that they have preferential treatment with them that distinguishes them.

Group 4. The staff must treat the client with affection, keeping their distance and taking care not to use the quasi-lexical elements described. In addition, they must take care of the tone so as not to use the authoritarian one. They can be friendly with customers, without excesses.

Group 5. Staff must keep their distance and take care not to use affectionate gestures or personal treatment, as well as expressions that can be perceived as affectionate. They must maintain an interested posture without effusive expressions.

Group 6. The staff must be very careful in dealing with these clients. They require docile treatment from the staff. It is recommended to refrain from physical contact and from making changes in the melodic and tonal curve of the voice. The interlocutor's gaze should not be diverted, so that it is not considered as inattention and avoid using illustrative gestures as much as possible.

Finally, two training workshops will be held. First, the contents of the non-verbal communication are offered, such as importance, functions, components, and individual preferences. In a second workshop, direct advice is offered to workers for the development of personalized attention actions for non-verbal communication. Finally, suggestions for customer treatment are exchanged with workers, and they are considered according to individual and collective opinions.

THIRD STAGE: Assessment of the transformation.

OBJECTIVE OF THE STAGE: Assess transformations in the subjects involved in the research.

In this final stage, actions are carried out (Table 1, actions 7 and 8), aimed at determining the opinion of the workers, as well as the preparation achieved with the proposed training program.

Action 7 will be carried out through the documentary review of the complaints reports from the quality and customer service department and the reviews left by customers on the TripAdvisor site (www.tripadvisor.com, accessed on 14 April 2021).

In Action 8, an analytical cut is made on the filling of the self-transformation record, (Appendix A) through the exchange with the sample of selected workers, so that they expose each of their advances or setbacks in knowledge and level of preparedness reached on the subject.

Workers are asked to send in writing, after being discussed collectively, the main suggestions that, as participants in the implementation of the training program, contribute to its improvement. The workers are asked to show in an artistic way the transformation that they have been able to experience in their way of acting based on what they have learned in the different work sessions (painting, modeling, poetry, staging, and storytelling). 
Finally, they are asked to develop the Positive-Negative-Interesting technique [38] to record the criteria issued by the participants in the written memory of the application of the training program.

\section{Discussion and Results}

Several studies have been made to propose training programs to increase communication skills, mainly for healthcare sector. Omura et al. [39] made a systematic review of the effectiveness of assertiveness communication training programs for healthcare professionals and students. Their review showed positive outcomes regarding all analyzed training programs, showing an impact in the performance of the healthcare personnel. Another studied within the medical sector showed benefits of training programs in the professional care for persons with intellectual disabilities and challenging behavior [40].

In the tourism industry, there is little work done regarding training programs to improve communication skills. One of them is the work by Sharma [23], who studied aspects of non-verbal communication (such as self-presentation) in tourism guides training program in Nepal. However, this study was not designed to improve tourism itself; it rather showed an increase in the abilities of the tourist guides to "commodify their identities in ways that construct both contrasts and similarities with their clients" [23]. Last year, another study was published, focused on training the tourism staff in facial expression and emotion recognition abilities [22]. Although the study finds an increase in the ability of the staff to recognize facial expressions and related emotions, they consider that much work is needed to increase the staff abilities in terms of using and managing emotions.

The proposed training program is focused on increasing the preparation of the staff of the Sol Cayo Guillermo hotel, to increase their communication skills, to be able of obtaining a better communication with the clients and give them personalized attention, by taking into account their non-verbal preferences.

To give greater foundation to the actions to improve the situation raised within the Soft Systems Methodology, the evaluation of the proposed training program is generated. To follow the concordance of the research, the functions expressed in the training program described above and the fulfillment of its purpose are conducted, which is based on the hypothesis developed at the beginning of this research.

General hypothesis: the proposal of a training program based on the components of the customer service personalization system, based on non-verbal communication and the CRM approach, can make the worker-customer communication relationship more effective to increase customer profitability in four-star hotels in Cuba.

To test this hypothesis, the criterion of experts was used. The criteria followed to evaluate the quality and effectiveness of research in scientific practice are [41]:

- Formal scientists: they use the current, novelty, reliability, and significance of results as indicators.

- Economic: they use the relationship of resources used and the profit achieved, in addition to the relationship of the time of completion and the introduction of results.

- Of practical use: they use the level of generalization and practical satisfaction of the result.

- Metrics: they use the indicators of significance, veracity, reliability, and statistical techniques.

- Qualimetric: they use evaluation criteria through experts.

In the research, qualimetric criteria are applied to validate the system by expert criteria. An expert is understood to be the individual capable of offering conclusive appraisals of a problem and making recommendations regarding its fundamental moments with a maximum of competence.

In this case, a study is initially carried out to determine who will be the specialists who evaluate the training program based on the components of the customer service personalization system, based on non-verbal communication and the CRM approach. Then, a survey is applied to determine their competence and the corresponding analysis is carried 
out. Based on the results obtained, questions are asked only to specialists who, due to their level of competence, have been selected as experts. Finally, to corroborate the results, the established methodology is applied and the results are processed.

In total, 26 specialists were selected as possible experts, taking into account their experience in the research topic and their scientific-technical qualification, as well as their professional experience and training. These specialists include the staff of the Quality and Customer Service department of the Sol Cayo Guillermo hotel (5), the hotel management staff (3), the staff of the Customer Service department of other Meliá Cuba hotels (16), and Doctor of Sciences from the province of Ciego de Ávila (2) related to the subject.

To calculate the expert's competence, a measure K (Equation (1)) is used, which in turn is based on two variables, kc and ka. The expert's competence includes elements such as his activity, his knowledge on the subject, and the depth of these.

$$
\mathrm{K}=\frac{1}{2}(\mathrm{kc}+\mathrm{ka})
$$

where $\mathrm{kc}_{\mathrm{c}}$ is the information coefficient of the expert on the subject being analyzed. This value is calculated on the basis of the expert's own assessment on a scale from 0 to 10 and multiplied by 0.1 , while ka is the expert's argumentation coefficient, determined as a result of the sum of the points achieved from a standard table.

To determine the degree of competence, a survey was applied to the specialists (Appendix B), with the objective of selecting the degree of influence of the different sources of argumentation. From these data, the competence of the specialists began to be determined to select those with a medium or high level. To determine the classification of the experts, the following rules were followed:

- If $0.8<\mathrm{K} \leq 1.0$, then the coefficient of competence is high.

- If $0.5<\mathrm{K} \leq 0.8$, then the coefficient of competence is medium.

- If $\mathrm{K} \leq 0.5$, then the coefficient of competence is low.

Thus, of the 26 specialists on the subject selected, 24 are considered experts. To corroborate the impact of the proposed training program on the worker-client communicative relationship to increase client profitability in four-star hotels in Cuba, a guide was prepared (Appendix C) that contains the following aspects to be evaluated by the experts:

1. Quality of the information obtained.

2. Structure of the training program.

3. Use of new information and communication technologies.

4. Coherence of the proposed actions.

5. Applicability of the training program.

Taking into account the results of the application of the survey and according to the scale, a double-entry table is constructed (Table 2), showing the opinion of the experts on each question. After obtaining the results of the expert appraisal, it is necessary to test the level of agreement between the experts to give the research greater reliability. Thus, it is necessary to check the degree of coincidence of the evaluations made by the experts.

To conduct this test, the Kendall Coefficient of Concordance [42] was applied, which is a statistical measure to establish the coincidence or agreement between observations, objects, or people.

The data in Table 2 were processed in SPSS (Statistical Product and Service Solutions) [43], a particularly useful and simple tool for statistical processing and analysis. Thus, it was possible to apply the Kendall $\mathrm{W}$ test to the expert evaluations and determine whether the experts' criteria for corroborating the incidence of the system is significant. 
Table 2. Responses of the experts while evaluating the five aspects of the proposed training program.

\begin{tabular}{cccccc}
\hline Expert & Aspect $\mathbf{1}$ & Aspect 2 & Aspect 3 & Aspect 4 & Aspect 5 \\
\hline 1 & 5 & 5 & 5 & 5 & 4 \\
2 & 5 & 5 & 5 & 5 & 5 \\
3 & 5 & 5 & 5 & 5 & 4 \\
4 & 5 & 5 & 5 & 5 & 5 \\
5 & 5 & 5 & 4 & 5 & 4 \\
6 & 5 & 5 & 5 & 5 & 5 \\
7 & 5 & 4 & 5 & 5 & 5 \\
8 & 5 & 5 & 5 & 5 & 4 \\
9 & 5 & 5 & 5 & 5 & 4 \\
10 & 5 & 5 & 5 & 5 & 5 \\
11 & 5 & 5 & 4 & 5 & 4 \\
12 & 5 & 5 & 5 & 5 & 5 \\
13 & 5 & 5 & 5 & 5 & 5 \\
14 & 5 & 5 & 5 & 5 & 4 \\
15 & 5 & 4 & 5 & 5 & 5 \\
16 & 5 & 4 & 5 & 5 & 4 \\
17 & 5 & 5 & 5 & 5 & 5 \\
18 & 5 & 5 & 4 & 5 & 5 \\
19 & 5 & 5 & 5 & 5 & 5 \\
20 & 5 & 5 & 5 & 5 & 5 \\
21 & 5 & 5 & 5 & 5 & \\
22 & 5 & 5 & 5 & 5 & \\
23 & 5 & 5 & 5 & 5 & 5 \\
24 & 5 & 5 & 5 & 5 & 5 \\
\hline
\end{tabular}

For this, a significance level alpha $=0.05$ was used for $95 \%$ confidence, and specific hypotheses were proposed:

Hypothese 1 (H0). There is no coincidence in the criteria of the experts.

Hypothese 2 (H1). There is agreement in the criteria of the experts.

The SPSS showed that the Kendall W coefficient has a value of 0.180 for an asymptotic significance of 0.029 . As the significance is less than the alpha value $(0.029<0.05)$, it falls in the rejection region; therefore, $\mathrm{H} 0$ is rejected and $\mathrm{H} 1$ is accepted, thus leaving a coincidence in the criteria of the experts for a confidence of the $95 \%$.

Based on these results, it can be concluded that the experts agree that the proposed training program will have a positive impact on the worker-client communication relationship to increase customer profitability in four-star hotels in Cuba. In this way, it is considered that the hypothesis raised in the research is accepted.

The limitations of our study are as follows:

- The number of staff involved in the training program was low, due to only the staff of the Sol Cayo Guillermo hotel being involved and there being many other hotels in the Jardines del Rey touristic area.

- The study only considered three of the five subsystems of the non-verbal communication system proposed by Rey-Benguría [44]. The physiological and the preferred sensorial subsystems were not considered, due to the difficult of measurement, and due to the data collected by Tusell-Rey et al. Reference [25] does not include such information.

- We were unable to assess the effectiveness of the training program: due to the pandemic outbreak of COVID-19, the hotel was temporary closed, and the staff was temporary reallocated in other hotels of the Jardines del Rey area.

As new lines of future research, we want to assess other non-verbal aspects of the communication, as well as finish the assessment of the effectiveness of the proposed 
training program. We also want to increase the scope of the training program to train the staff of other hotels.

\section{Conclusions}

When studying and interpreting the current state of non-verbal communication and the CRM approach and its application to the tourism field, a lack of research that integrates both elements is evident, despite the importance that non-verbal communication represents the acts of presenting and dressing the processes of social interaction in general and in customer service. Research on this topic agrees on the need to improve effectiveness in the communication process with the client to facilitate communicative success and help in conflict resolution, which is why the need for training in certain skills of professionals is evident.

Using the Soft Systems Methodology, two relevant systems were considered, and these were operationalized in the proposed model. A survey was elaborated to determine the non-verbal preferences of the clients, and thus, a data bank was built from it. Once the relevant systems were operationalized, they were contrasted through the application of Computational Intelligence in order to obtain and characterize customer groups.

A training program based on the components of the customer service personalization system was proposed, based on non-verbal communication and the eCRM approach to make the worker-customer communication relationship more effective at the Sol Cayo Guillermo hotel, Cuba. The proposed training program consisted of three stages, conceived in this way to sensitize staff on the need for personalized treatment and provide them with the main non-verbal communication tools in their usual work interactions. The training program was validated by the criteria of experts, who agree that the proposed training program will have a positive impact on the communicative worker-client relationship to increase the profitability of the client in four-star hotels in Cuba.

The results of this research can be extended to other four-star hotels in Cuba and even applied in other international destinations with similarities in the problem studied. To achieve its adequate utility, the elaboration of a diagnosis and data collection is essential. Change agents must be the first interested and willing to work together; therefore, it is advisable to take into account the opinion of the actors directly involved with customer service. It is also considered pertinent to increase the customer data set, by applying the proposed questionnaire to new customers of the Sol Cayo Guillermo hotel as well as in other hotel facilities where the proposal can be considered.

The goal of the article was fulfilled, due to the fact that we were able to design and to apply a training program to increase the preparation of the Sol Cayo Guillermo hotel staff to provide a personalized attention to the clients, according to their non-verbal preferences.

The variables to assess the non-verbal preferences of the clients are the essential of the non-verbal communication system (kinesics, paralanguage, and proxemic), in addition to being the most feasible to evaluate in clients. We believe that it will be the role of future work to corroborate the influence of other variables of non-verbal communication on customer satisfaction.

Author Contributions: Conceptualization, C.C.T.-R. and C.F.R.-B.; methodology, R.T.-P.; software, Y.V.-R.; validation, C.C.T.-R., C.F.R.-B., R.T.-P., and Y.V.-R.; formal analysis, R.T.-P.; investigation, C.C.T.-R., C.F.R.-B., and Y.V.-R.; data curation, C.C.T.-R.; writing-original draft preparation, C.C.T.-R. and C.F.R.-B.; writing-review and editing, Y.V.-R. and R.T.-P.; supervision Y.V.-R. All authors have read and agreed to the published version of the manuscript.

Funding: This research received no external funding.

Institutional Review Board Statement: The study was conducted according to the guidelines of the Declaration of Helsinki and approved by the Ethics Committee of HOTEL SOL CAYO GUILLERMO (with number 01/2019 and approval date 17 December 2019).

Informed Consent Statement: Informed consent was obtained from all subjects involved in the study. 
Data Availability Statement: All surveys are given as appendixes.

Acknowledgments: The authors would like to thank the Instituto Politécnico Nacional (Secretaría Académica, Comisión de Operación y Fomento de Actividades Académicas, Secretaría de Investigación y Posgrado, Escuela Superior de Turismo, Centro de Investigación en Computación, and Centro de Innovación y Desarrollo Tecnológico en Cómputo), the Consejo Nacional de Ciencia y Tecnología, and Sistema Nacional de Investigadores for their economic support to develop this work.

Conflicts of Interest: The authors declare no conflict of interest.

\section{Appendix A. Self-Transformation Record}

Instruction: Check the option you consider corresponds to the contribution to your transformation. On the other hand, you can issue criteria in this regard.

\begin{tabular}{|c|c|c|c|}
\hline & Highly Effective & Relatively Effective & Noneffective \\
\hline \multicolumn{4}{|c|}{$\begin{array}{l}\text { Theoretical knowledge about non-verbal } \\
\text { communication }\end{array}$} \\
\hline \multicolumn{4}{|c|}{$\begin{array}{l}\text { Ability to manage non-verbal preferences } \\
\text { Involvement in the task }\end{array}$} \\
\hline Involvement in the task & & & \\
\hline
\end{tabular}

\section{Appendix B. Survey to the Specialists}

Instruction: Due to your well-known experience as an expert in the tourism field, we need your cooperation to validate a training program based on the components of the customer service personalization system, based on non-verbal communication and the CRM approach that can make the communicative worker-client relationship more effective to increase client profitability in four-star hotels in Cuba.

Vocational training:

Current occupation:

Tourism experience:

1. In the table that appears below, a scale from 1 to 10 is proposed, which goes in ascending order from ignorance to deep knowledge. Check the grid that you consider corresponds to the degree of knowledge you have on the subject: "Communicative relationship and customer profitability in a CRM approach, for hotel facilities".

\begin{tabular}{llllllllll}
\hline 1 & 2 & 3 & 4 & 5 & 6 & 7 & 8 & 9 & 10 \\
\hline
\end{tabular}

2. Mark with an $X$ the sources that you consider having influenced your knowledge on the subject, to a high, medium or low degree.

\begin{tabular}{|c|c|c|c|}
\hline \multirow{2}{*}{ Sources of Argumentation } & \multicolumn{3}{|c|}{ Degree of Influence in Your Opinion } \\
\hline & High & Medium & Low \\
\hline \multicolumn{4}{|l|}{ Theoretical analysis carried out } \\
\hline \multicolumn{4}{|l|}{ Professional experience } \\
\hline \multicolumn{4}{|l|}{ Works of national authors } \\
\hline \multicolumn{4}{|l|}{ Works of foreign authors } \\
\hline \multicolumn{4}{|c|}{ Your own knowledge of the status of the } \\
\hline \multicolumn{4}{|c|}{ research problem } \\
\hline \multicolumn{4}{|l|}{ Your intuition } \\
\hline
\end{tabular}




\section{Appendix C. Evaluation of the Proposed Training Program}

Instruction: With the aim of validating the training program based on the components of the customer service personalization system, based on non-verbal communication and the CRM approach to make the worker-customer communicative relationship more effective to increase customer profitability in four-star hotels in Cuba; evaluate, using the proposed scale, the aspects listed below. Please check the scale accordingly.

1. Quality of the information obtained.

\begin{tabular}{lllll}
\hline Highly suitable & Very suitable & Suitable & Less suitable & Non suitable \\
\hline & & \\
\hline
\end{tabular}

2. Structure of the training program.

\begin{tabular}{|c|c|c|c|c|}
\hline Highly suitable & Very suitable & Suitable & Less suitable & Non suitable \\
\hline
\end{tabular}

3. Use of new information and communication technologies.

\begin{tabular}{lllll}
\hline Highly suitable & Very suitable & Suitable & Less suitable & Non suitable \\
\hline
\end{tabular}

4. Coherence of the proposed actions.

\begin{tabular}{|c|c|c|c|c|}
\hline Highly suitable & Very suitable & Suitable & Less suitable & Non suitable \\
\hline
\end{tabular}

5. Applicability of the training program.

\begin{tabular}{|c|c|c|c|c|}
\hline Highly suitable & Very suitable & Suitable & Less suitable & Non suitable \\
\hline
\end{tabular}

\section{References}

1. Papaioannou, A.; Kariofyllas, C.; Koronios, K.; Kourtesopoulou, A.; Kriemadis, A. Exploring E-CRM application: The case of tourism and hospitality industry in greece. J. Reg. Socio-Econ. Issues (Jrsei) 2014, 4, 75-84.

2. Sigala, M. eCRM 2.0 applications and trends: The use and perceptions of Greek tourism firms of social networks and intelligence. Comput. Hum. Behav. 2011, 27, 655-661. [CrossRef]

3. Mastorakis, G.; Trihas, N.; Perakakis, E.; Kopanakis, I. E-CRM in tourism exploiting emerging information and communication technologies. Anatolia 2015, 26, 32-44. [CrossRef]

4. Dubihlela, J.; Molise-Khosa, P. Impact of e-CRM implementation on customer loyalty customer retention and customer profitability for hoteliers along the Vaal Meander of South Africa. Mediterr. J. Soc. Sci. 2014, 5, 175-183. [CrossRef]

5. Ab Hamid, N.R.; Cheng, A.Y.; Akhir, R.M. Dimensions of E-CRM: An empirical study on hotels' web sites. J. Southeast Asian Res. 2011, 2, 1-15. [CrossRef]

6. Mekkamol, P.; Piewdang, S.; Untachai, S. Modeling e-CRM for community tourism in Upper Northeastern Thailand. Procedia-Soc. Behav. Sci. 2013, 88, 108-117. [CrossRef]

7. Sun, S.; Wei, Y.; Tsui, K.-L.; Wang, S. Forecasting tourist arrivals with machine learning and internet search index. Tour. Manag. 2019, 70, 1-10. [CrossRef]

8. Yang, Q.; Li, J.; Zou, X. Big Data and Higher Vocational and Technical Education: Green Tourism Curriculum. In Proceedings of the 2019 International Conference on Big Data and Education, London, UK, 30 March-1 April 2019; pp. $108-112$.

9. Yu, C.; Zhu, X.; Feng, B.; Cai, L.; An, L. Sentiment Analysis of Japanese Tourism Online Reviews. J. Data Inf. Sci. 2019, 4, 89-113. [CrossRef]

10. Zhang, F.; Jiang, Q.; Wang, Z. Forecasting Mode of Sports Tourism Demand Based on Support Vector Machine. In Proceedings of the 5th International Conference on Frontiers of Educational Technologies, Beijing, China, 1-3 June 2019; pp. 154-158.

11. Zhang, K.; Chen, Y.; Li, C. Discovering the tourists' behaviors and perceptions in a tourism destination by analyzing photos' visual content with a computer deep learning model: The case of Beijing. Tour. Manag. 2019, 75, 595-608. [CrossRef]

12. Purohit, A.; Thakar, U. Role of information and communication technology in improving loyalty program effectiveness: A comprehensive approach and future research agenda. Inf. Technol. Tour. 2019, 21, 259-280. [CrossRef] 
13. Lu, Q.S.; Miller, R. How social media communications combine with customer loyalty management to boost green retail sales. J. Interact. Mark. 2019, 46, 87-100. [CrossRef]

14. Keikha, A.; Nouridelavar, M.; Keikha, H. The Effect of Integrated Marketing Communication (IMC) on Customer Relationship Management in Private Banks in Zahedan City. Manag. Res. 2020, 12, 279-304.

15. Nwaeke, L.I.; Obiekwe, O. Impact of manpower training and development on organizational productivity and performance: A theoretical review. Eur. J. Bus. Manag. 2017, 9, 153-159.

16. Jensen, M. Integrated communication systems and kinesic code-switching in interpersonal interaction. J. Stud. Soc. Sci. 2016, 14, 127-165.

17. Vella, M. Feeling Spaces: The Effects of Proxemics and Non-Verbal Communication in Seating Design. Bachelor's Thesis, University of Malta, MSD, Malta, 2016.

18. Sohn, E.-M.; Lee, K.-W. The effect of chefs' nonverbal communication in open kitchens on service quality. J. Foodserv. Bus. Res. 2018, 21, 483-492. [CrossRef]

19. Van Rooyen, E. Developing Tomorrow's Leaders: Applying Neuro-Linguistic Programming Techniques in Public Affairs Education and Human Resources Development. In Proceedings of the 3rd International Conference on Public Administration and Development Alternatives, Saldahna Bay, South Africa, 4-6 July 2018.

20. Kotera, Y.; Sheffield, D.; Van Gordon, W. The applications of neuro-linguistic programming in organizational settings: A systematic review of psychological outcomes. Hum. Resour. Dev. Q. 2019, 30, 101-116. [CrossRef]

21. Lavan, I. NLP in business-or more than a trip to the zoo. Ind. Commer. Train. 2002, 34, 182-187. [CrossRef]

22. Koc, E.; Boz, H. Development of hospitality and tourism employees' emotional intelligence through developing their emotion recognition abilities. J. Hosp. Mark. Manag. 2020, 29, 121-138. [CrossRef]

23. Sharma, B.K. Training workers for intercultural communication in tourism. Lang. Intercult. Commun. 2018, 18, 408-423. [CrossRef]

24. Checkland, P. Towards a systems-based methodology for real-world problem solving. J. Syst. Eng. 1972, 3, 87-116.

25. Tusell-Rey, C.C.; Tejeida-Padilla, R.; Camacho-Nieto, O.; Villuendas-Rey, Y.; Yáñez-Márquez, C. Improvement of Tourists Satisfaction According to Their Non-Verbal Preferences Using Computational Intelligence. Appl. Sci. 2021, 11, 2491. [CrossRef]

26. Checkland, P. Soft systems methodology: A thirty year retrospective. Syst. Res. Behav. Sci. 2000, 17, S11-S58. [CrossRef]

27. Sharma, R.; Zhang, C.; Wingreen, S.C.; Kshetri, N.; Zahid, A. Design of Blockchain-based Precision Health-Care using soft systems methodology. Ind. Manag. Data Syst. 2019, 120, 3. [CrossRef]

28. Iriani, A.; Manongga, D. Using soft systems methodology as an approach to evaluate cheating in the national examination. J. Theor. Appl. Inf. Technol. 2018, 96, 3344-3355.

29. Khayame, H.A.; Abdeljawad, M.M. Systems thinking in upstream social marketing: Using soft systems methodology to improve midwifery policy in Jordan. Soc. Mark. Q. 2020, 26, 167-183. [CrossRef]

30. El-Taliawi, O.G.; Hartley, K. The COVID-19 crisis and complexity: A soft systems approach. J. Contingencies Crisis Manag. 2021, 29, 104-107. [CrossRef]

31. Damenu, T.K.; Beaumont, C. Analysing information security in a bank using soft systems methodology. Inf. Comput. Secur. 2017, 25, 240-258. [CrossRef]

32. Stamoulis, D.S. Information systems for the social administration using the soft systems methodology. Int. J. Appl. Syst. Stud. 2020, 9, 1-10. [CrossRef]

33. Valle-Lima, A.D. La investigación pedagógica. In Otra Mirada; Editorial Pueblo y Educación: La Habana, Cuba, 2012.

34. Teixeira, G.F.G.; Junior, O.C. How to make strategic planning for corporate sustainability? J. Clean. Prod. 2019, $230,1421-1431$. [CrossRef]

35. Clayton, M.; Headley, A. The use of behavioral skills training to improve staff performance of discrete trial training. Behav. Interv. 2019, 34, 136-143. [CrossRef]

36. Erath, T.G.; DiGennaro Reed, F.D.; Blackman, A.L. Training human service staff to implement behavioral skills training using a video-based intervention. J. Appl. Behav. Anal. 2021. [CrossRef] [PubMed]

37. Morozov, M.; Morozova, N. Innovative staff training strategies for the tourism and hospitality industry. In Proceedings of the 5th International Conference on Economics, Management, Law and Education (EMLE 2019), Russian New University, Moscow, Russia, 11-12 October 2019; pp. 393-396.

38. Harris, J. Positive, negative, and interesting: A strategy to teach thinking and promote advocacy. Am. J. Health Educ. 2008, 39, 184-186. [CrossRef]

39. OMT. Available online: http:/ / www2.unwto.org (accessed on 18 March 2021).

40. Truong, A.; Alverbratt, C.; Ekström-Bergström, A.; Antonsson, H. Caring for persons with intellectual disabilities and challenging behavior: Staff experiences with a web-based training program. Front. Psychiatry 2021, 12. [CrossRef]

41. Bobadilla-Álvarez, M.; Zavala de la Cruz, F.; Ramírez-Apolinario, E.; González-Castro, J.; Mendoza-López, A.; Mormontoy-Laurel, W.; Palomino-Cárnedas, J.; Yglesias-Jauregui, M. Metodología de la Investigación; Bobadilla-Álvarez, M., Ed.; Editorial Huaraz: Huaraz, Perú, 2008.

42. Kendall, M.G. A new measure of rank correlation. Biometrika 1938, 30, 81-93. [CrossRef]

43. Verma, J. Data Analysis in Management with SPSS Software; Springer Science \& Business Media: Berlin, Germany, 2012.

44. Rey-Benguría, C.F. Pedagogical Model for the Formation of the Non-Verbal Communication Competence in Educational Staff; University of Oriente: Santiago de Cuba, Cuba, 2006. (In Spanish) 